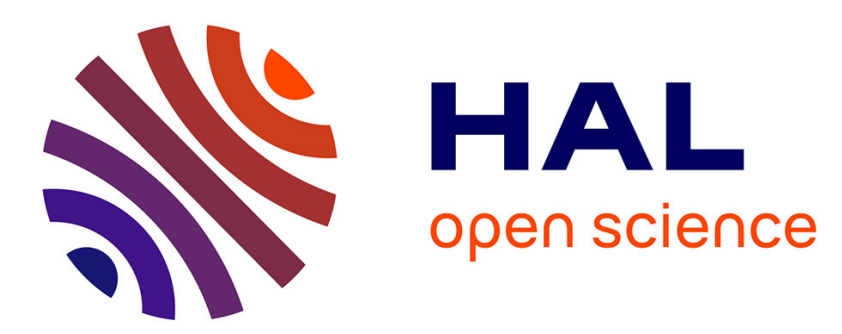

\title{
Structure and Implementation of a SIMO Multi-Standard Multichannel SDR Receiver
}

Pierre-Francois Morlat, Antonio Luna, Xavier Gallon, Guillaume Villemaud, Jean-Marie Gorce

\section{- To cite this version:}

Pierre-Francois Morlat, Antonio Luna, Xavier Gallon, Guillaume Villemaud, Jean-Marie Gorce. Structure and Implementation of a SIMO Multi-Standard Multichannel SDR Receiver. IEEE Radio and Wireless Symposium, Jan 2008, Orlando, United States. inria-00412054

\section{HAL Id: inria-00412054 https://hal.inria.fr/inria-00412054}

Submitted on 27 Nov 2009

HAL is a multi-disciplinary open access archive for the deposit and dissemination of scientific research documents, whether they are published or not. The documents may come from teaching and research institutions in France or abroad, or from public or private research centers.
L'archive ouverte pluridisciplinaire HAL, est destinée au dépôt et à la diffusion de documents scientifiques de niveau recherche, publiés ou non, émanant des établissements d'enseignement et de recherche français ou étrangers, des laboratoires publics ou privés. 


\title{
Structure and Implementation of a SIMO Multi-Standard Multi- channel SDR Receiver
}

\author{
P.F. Morlat, A. Luna, X. Gallon, G. Villemaud, J.M. Gorce \\ CITI Insa-Lyon, Villeurbanne, 69621, France
}

\begin{abstract}
This article presents the structure of a multiantenna multi-channel and multi-standard receiver based on Software Defined Radio (SDR) concept. At this time our work is focused on 802.11g and 802.11b signals cohabiting in a $40 \mathrm{MHz}$ frequency bandwidth around the $2.4 \mathrm{GHz}$ RF carrier frequency. Using classical Single Input Multiple Output (SIMO) processing, these incoming signals are combined to increase transmission performances and to mitigate fading effect. Simulated and measured results of our structure are given and a description of the real proposed architecture is detailed.
\end{abstract}

Index Terms - SIMO processing, WLAN standard, SDR receiver, multi-channel multi-standard receiver.

\section{INTRODUCTION}

The future of wireless communications can be view as numerous standards operating together. Reconfigurable receiver is an important feature in the solution of providing interoperability of transceivers in a number of different wireless systems. The ideal universal receiver sampling the incoming signals just after a RF stage is very seducing but not realistic at this time due to limitations in sampling capabilities for high frequency systems. In this context, Software-defined radio (SDR) [1,2] principles have attracted more and more attention. We can then imagine reconfigurable receiver able to deal with predefined transmission standards. An important number of contributions on SDR can be found in the literature and several key-items of different aspects of the signal processing chain are discussed: sample rate adaptation [3], RF front end design [4] as example, and several SDR test bed platforms are described $[5,6]$.

Our work combines several attractive and relevant principles in order to increase data rate, quality of service and flexibility in the same architecture. First of all, based on SDR concept we propose a multi-standard approach. Indeed, the receiver we describe is able to deal with WLAN 802.11g and 802.11b standards. In this way, each technology will no longer relies on a particular chip, but on a software package, allowing dynamical changes and also parallel decoding. Then a particular attention should be paid on calculation resources, assuming a maximum reuse of basic functions for all standards (FFT, filtering) and a precise dimensioning to achieve real time operations.

Moreover, it is well known that multiplying antennas, even from the only receiver point of view offers a high potential to compensate radio channel fading and interference. That is why 4 receiving antennas are used by our receiver. Several copies of the same emitted signal are available and using SIMO processing a great benefit could be taken from spatial diversity, especially in large angular spread configuration which corresponds to the working environment of WLAN transmissions. At this time SIMO algorithms we use are based on the classical and well known Minimum Mean Square Error (MMSE) criterion; because of its low complexity and its good adaptation to WLAN transmissions using training sequences at the beginning of each frame. But depending on the treated signal and the propagation channel, different alternatives of the same algorithm are used in order to have the better trade off complexity - performances increasing for each WLAN standard. [7] describes classical SIMO processing we use, applied in the case of $802.11 \mathrm{~g}$ and $802.11 \mathrm{~b}$ transmissions.

Another particularity of the proposed structure is the multi-channel approach. Classical receivers, after selection of its allowed channel for communication, operate a frequency tuning in its RF part to only filter this chosen band, naturally operating an adjacent channel rejection. 802.11 transmission based on $84 \mathrm{MHz}$ large band shared between up to 14 overlapping $20 \mathrm{MHz}$ channels is a very relevant example of this phenomena. That is why designing a receiver sampling a $40 \mathrm{MHz}$ bandwidth instead of a bandwidth corresponding to only one communication channel seems to be interesting. This allows taking advantage of larger numerical information of the desired signal together with interferes. Then different techniques of interference mitigation, channel rejection [8], or parallel decoding can be involved.

All of those multi-* approaches are combining in the same test platform composed by antenna and RF frontend, numerical processing stage with DSP and FPGA, and a PC to combine received signals thanks SIMO processing and compute transmission BER. This article is structured as follow: first part describes results obtained by 
simulation and measure using software demonstrator developed with ADS from Agilent Technologies [9] in different working conditions. Then, the second part presents the structure developed platform.

\section{SIMO Multi-Standard Multi-Channel Receiver PERFORMANCES}

As presented before, combining multi-antenna, multichannel and multi-standard principles in the same receiver seem to be a very promising issue to increase wireless transmission performances. However, several parameters like antenna coupling, channel correlation and also propagation channel properties have an important influence on SIMO performances [10]. That is why a software demonstrator simulating the running of a 4 antennas receiver and able to deal with $802.11 \mathrm{~g} / \mathrm{b}$ signals in a $40 \mathrm{MHz}$ bandwidth was developed using ADS software. Different SIMO algorithms, configurations of running (space between two interest communication channels), and propagation channel characteristics could be chosen to have a better estimation of the performances of our system in realistic working conditions. Moreover, thanks the compatibility with Agilent equipment, a complete multi-antenna $(2 \times 2)$ test bed radio platform was installed in order to rapidly test and evaluate performances of any stage of wireless transmission [11]. Due to the current capacity of our platform, it is possible to record only 2 incoming signals simultaneous. However it is sufficient to introduce channel correlation and antenna coupling in our measure. That is why, even if the developed demonstrator is able to run with 4 receiving antennas, only $1 \times 2$ SIMO performances are presented.

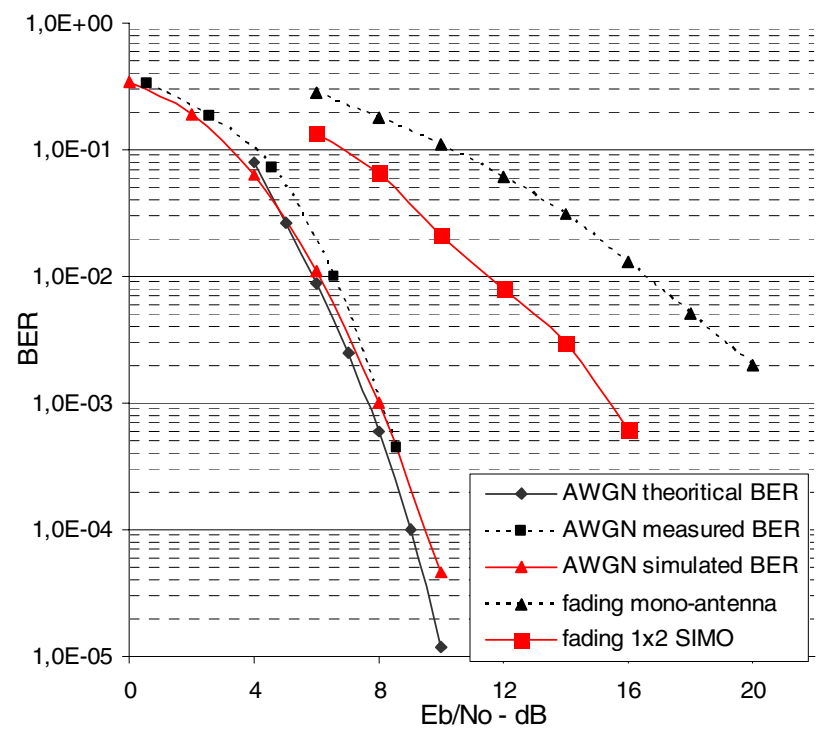

Fig. 1. BER vs. Eb/No for 802.11 b transmission
Fig.1 gives measured and simulated performances of an 11 Mbps 802.11b transmission in different working conditions. Firstly a very good match between AWGN theoretical, simulated, and measured Bit Error Rate (BER) curves is observed. Furthermore, about $5 \mathrm{~dB}$ of gain could be also observe in the case of a transmission under a fast fading multi-path propagation channel between the single antenna receiver and the 2 antennas structure using SIMO processing to combine received signals.

Finally, table 1 presents BER values in the case of the terminal is dealing with two recorded signals of each standard after propagation under a measured AWGN channel. Both signals are emitted to a sufficient level to guaranty no transmission error in the case of a mono standard communication.

TABLE I

Multi-Channel Multi-Standard Performances

\begin{tabular}{|l|l|l|l|l|}
\hline $\begin{array}{l}\text { channel } \\
\text { spacing } \\
(\mathrm{MHz})\end{array}$ & $\begin{array}{l}802.11 \mathrm{~b} \\
\text { single } \\
\text { antenna }\end{array}$ & $\begin{array}{l}802.11 \mathrm{~b} \\
1 \times 2 \\
\text { SIMO }\end{array}$ & $\begin{array}{l}802.11 \mathrm{~g} \\
\text { single } \\
\text { antenna }\end{array}$ & $\begin{array}{l}802.11 \mathrm{~g} \\
1 \times 2 \\
\text { SIMO }\end{array}$ \\
\hline 0 & 0.5 & 0.004 & 0.5 & 0.2 \\
\hline 5 & 0.45 & $4.9 .10^{-4}$ & 0.45 & 0.05 \\
\hline 10 & 0.16 & 0 & 0.25 & 0.03 \\
\hline 15 & 0 & 0 & 0 & 0 \\
\hline
\end{tabular}

In a $36 \mathrm{MHz}$ bandwidth, two $20 \mathrm{MHz}$ signals emitted on carrier frequency spaced one of the other by $15 \mathrm{MHz}$ could easily cohabit. As it could be expected, the more channels are spaced, the better are transmission performances. With these results, we can observe a great performances increasing using a 1x2 SIMO architecture even if only spatial diversity processing are used. On the other hand, in the case of two channels are $25 \%$ overlapped (channel spacing of $15 \mathrm{MHz}$ ), no transmission error is obtained, even if a single antenna receiver is used.

\section{THE SDR RECEIVER STRUCTURE}

This parts describes different operating stage we develop in order to treat RF incoming signals to the BER of the transmission computation.

\section{A. RF stage}

A 2 patches antenna spaced by a distance of $6 \mathrm{~cm}$ and providing each 2 channels of orthogonal polarization is used. So, we have 4 incoming signals to treat. This antenna is designed for $2.4 \mathrm{GHz}$ transmissions, and connected to the RF stage which allows the down conversion, and also an $80 \mathrm{MHz}$ sampling and a 10 bits coding of the complex signal.

\section{B. Numerical Processing}


The numerical processing is computed using two TSC43 PMC from VSystems [12]. Each board (fig. 2) comprises 4 clustered TigerSHARC DSP allowing a 300 $\mathrm{MHz}$ processing, a Xilinx Virtex-II FPGA and a $528 \mathrm{Mo} / \mathrm{s}$ PCI connection.

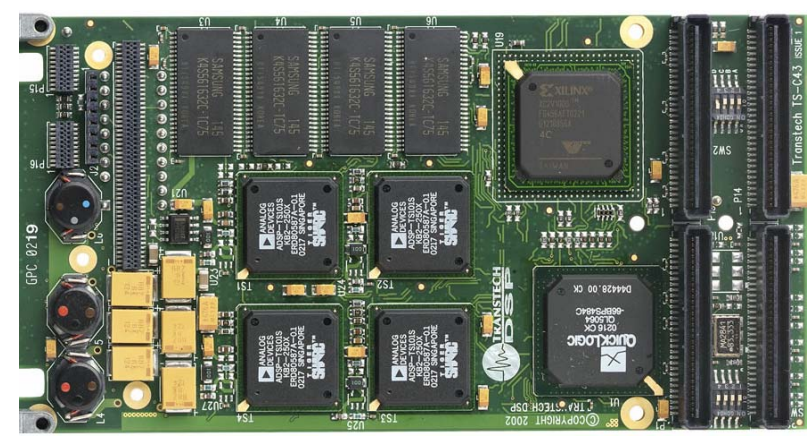

Fig. 2. The TS-C43 PMC board

FPGA and the RF stage are connected together by an external I/O connection of 100 pins, each one allowing a $100 \mathrm{MHz}$ connection. Between FPGA and DSP, a 150 $\mathrm{Mo} / \mathrm{s}$ connection is possible. However, rate of the incoming data from the RF stage to the FPGA, due to the sampling and the bit coding is $800 \mathrm{Mo} / \mathrm{s}$. An important data rate decreasing must be applied in the FPGA. Part D will describe functions of different numerical processing components. At the end, each DSP is connected to a 600 $\mathrm{Mo} / \mathrm{s}$ internal bus to access to SDRAM, Flash Memory and also the PCI gateway. Finally, the coding rate used with this TS-C43 board is 8 bits.

\section{PC connection}

Thanks the $528 \mathrm{Mo} / \mathrm{s}$ PCI connection, numerical data are send to a dual-processor $3 \mathrm{GHz}$ PC with a 4 Go RAM running Linux. The PC is used to combine the 4 numerical channels using different SIMO processing, and also to demodulate signals in order to compute BER of the transmission. At this stage of treatment, real time processing is not a really important parameter. Let us now list the most important functions used in the numerical processing stage.

\section{Numerical functions}

Each TS-C43 board has to deal with 2 reception channels. Remembering that our receiver must be able to deal with 2802.11 communications at the same time, one DSP has to permit the global signal processing for 1 incoming signal.

The major aim of the FPGA is to ensure an important data rate decreasing to make transmission to DSP possible. That is why the FPGA has to detect signal presence in the $40 \mathrm{MHz}$ bandwidth of interest, detect the
WLAN channel (carrier frequency) used and apply a 11 $\mathrm{MHz}$ filter around this carrier frequency on both complex channels (I and Q), which corresponds to a $22 \mathrm{MHz}$ channel bandwidth. That way, the data rate is $44 \mathrm{Mo} / \mathrm{s}$ and there is no problem for transmission to the DSP.

After a standard characterization and an adapted sampling according to the detected standard, numerical processing is applied to the signal.

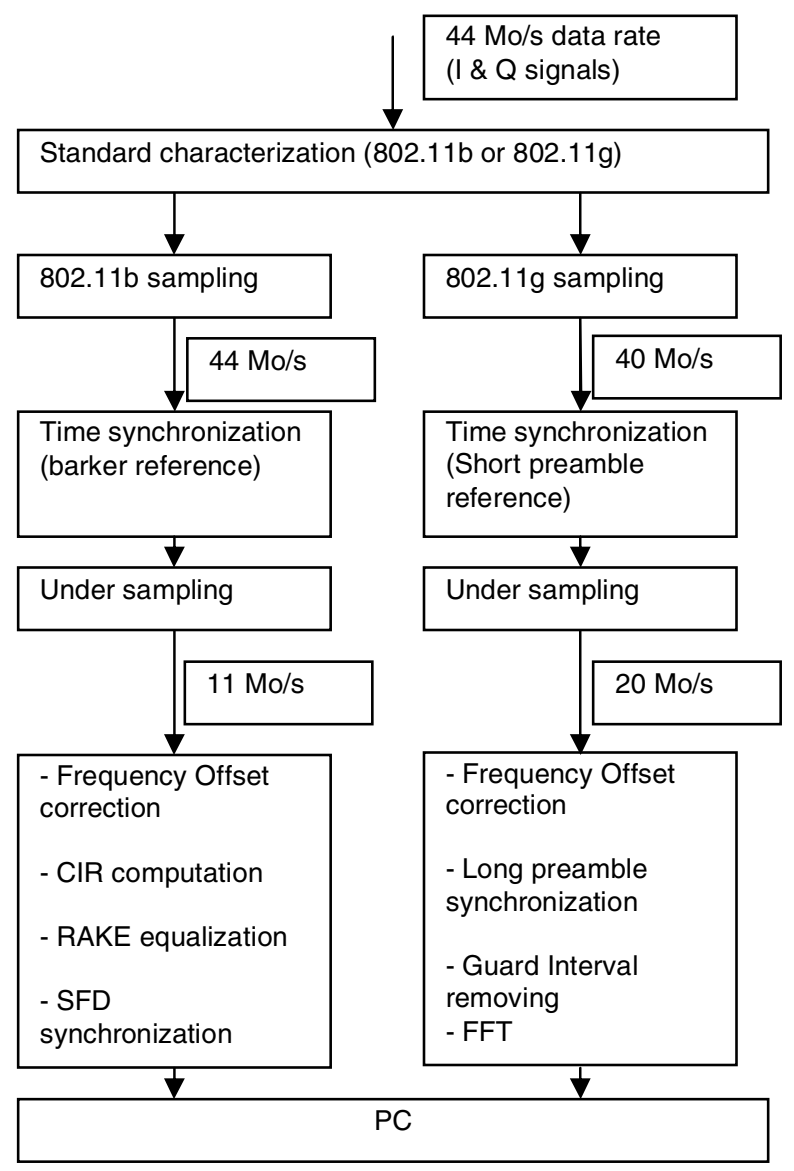

Fig. 3. Description of numerical functions

Fig.3 describes the different numerical functions implemented on each one of eight DSP. The Channel Impulse Response (CIR) for 802.11g transmissions is computed in frequency domain by the PC, before SIMO processing. In the case of $802.11 \mathrm{~b}$ transmission, barker dispreading is applied after the optimal SIMO coefficients computation. Thanks the several algorithms implemented, the data rate in the PCI transmission to PC is sufficient low.

At this time $802.11 \mathrm{~b}$ and $802.11 \mathrm{~g}$ processing have been tested with Matlab and implemented and tested with $\mathrm{VC}++$ software. $802.11 \mathrm{~b}$ receiver architecture is implemented on DSP and validated, but a lot work taking into account real time constraint has to be done. 


\section{CONCLUSION}

SDR concept combined with SIMO processing and multi-channel approach is a very promising issue to develop future wireless terminals ensuring robust and flexible transmissions. The aim of this work is to propose a SDR receiver architecture including these different approaches. RF properties, real time digital processing and also global system considerations have to be taken into account in order to propose a suitable architecture. Even if the SDR terminal structure and the role of different equipments of our platform depending on their computing capacities, are well defined at this time, a lot of work on the DSP implementation optimization has to be done in order to permit a real time processing.

\section{ACKNOWLEDGEMENT}

The authors wish to acknowledge France-Telecom R\&D who supports this work.

\section{REFERENCES}

[1] J. Mitola, "The software radio architecture", IEEE Communications magazine, vol. 33, no. 5, pp. 26-38, May 1995.

[2] A.R. Rhiemeir, "Modular Software-Defined Radio", Eurasip Journal on Wireless Communications and Networking, vol. 3, pp. 333-342, February 2005.

[3] M. Brandolini, et al., "Toward Multistandard Mobile Terminals-Fully integrated Receivers requirements and architectures", IEEE Transactions and Microwave Theory and Technology, vol. 53, no.3, March 2005.

[4] T. Hentschel, G. Fettweis, "Sample Rate conversion for software radio", IEEE Communications magazine, vol. 38, no. 8, pp. 142-150, 2000

[5] H.C. Miranda, P.C. Pinto, S.B. Silva, "A self reconfigurable receiver architecture for software radio systems", In proceedings of Radio and wireless Conference, August 2003.

[6] X. Xu, R. Bosisio, K. Wu, "Analysis and implementation of software defined Radio receiver platform", Asia Pasific Conference Proceedings, December 2005.

[7] P.F. Morlat, P.Mary, G. Villemaud, J.M. Gorce, M. Arndt, "Performance Validation of a multi-standard and multiantenna receiver", In Proceedings of European Conference on Antenna and Propagation, November 2006.

[8] P. Mary, J.M. Gorce, G. Villemaud, M. Dohler, M. Arndt, "Performance Analysis of Mitigated Asynchronous Spectrally-Overlapping WLAN Interfernce", In Proceedings of Wireless Communications and Networking Conference", Hong Kong, 2007.

[9] http://eesof.tm.agilent.com/products/ads_main.html

[10] D.K. Dietze, C.B. Dietrich, W.L. Stutzman, "Analysis of a two-ranches maximal ratio and selection diversity system with unequal SNRs and correlated inputs for a Rayleigh fading Channel", IEEE Transactions on wireless communications, vol. 1, Avril 2002.
[11] P.F. Morlat, H. Parvery, G. Villemaud, J. Verdier, J.M. Gorce, "Global System evaluation scheme for multiple antennas adaptive receivers", In Proceedings of European Conference on Wireless Technology, September 2006.

[12] http://www.vsystems.com/ 